\title{
RESEARCH
}

Open Access

\section{Salaried and voluntary community health workers: exploring how incentives and expectation gaps influence motivation}

Hermen Ormel ${ }^{1 *}$ D, Maryse Kok', Sumit Kane ${ }^{1}$, Rukhsana Ahmed ${ }^{2}$, Kingsley Chikaphupha ${ }^{3}$, Sabina Faiz Rashid ${ }^{4}$, Daniel Gemechu', Lilian Otiso ${ }^{6}$, Mohsin Sidat $^{7}$, Sally Theobald ${ }^{8}$, Miriam Taegtmeyer ${ }^{8}$ and Korrie de Koning ${ }^{1}$

\begin{abstract}
Background: The recent publication of the WHO guideline on support to optimise community health worker (CHW) programmes illustrates the renewed attention for the need to strengthen the performance of CHWs. Performance partly depends on motivation, which in turn is influenced by incentives. This paper aims to critically analyse the use of incentives and their link with improving CHW motivation.

Methods: We undertook a comparative analysis on the linkages between incentives and motivation based on existing datasets of qualitative studies in six countries. These studies had used a conceptual framework on factors influencing CHW performance, where motivational factors were defined as financial, material, non-material and intrinsic and had undertaken semi-structured interviews and focus group discussions with CHWs, supervisors, health managers and selected community members.

Results: We found that (a mix of) incentives influence motivation in a similar and sometimes different way across contexts. The mode of CHW engagement (employed vs. volunteering) influenced how various forms of incentives affect each other as well as motivation. Motivation was negatively influenced by incentive-related "expectation gaps", including lower than expected financial incentives, later than expected payments, fewer than expected material incentives and job enablers, and unequally distributed incentives across groups of CHWs. Furthermore, we found that incentives could cause friction for the interface role of CHWs between communities and the health sector.

Conclusions: Whether CHWs are employed or engaged as volunteers has implications for the way incentives influence motivation. Intrinsic motivational factors are important to and experienced by both types of $\mathrm{CHWs}$, yet for many salaried CHWs, they do not compensate for the demotivation derived from the perceived low level of financial reward. Overall, introducing and/or sustaining a form of financial incentive seems key towards strengthening CHW motivation. Adequate expectation management regarding financial and material incentives is essential to prevent frustration about expectation gaps or "broken promises", which negatively affect motivation. Consistently receiving the type and amount of incentives promised appears as important to sustain motivation as raising the absolute level of incentives.
\end{abstract}

Keywords: Community health workers, Motivation, Remuneration, Incentives, Low- and middle-income countries

\footnotetext{
* Correspondence: h.ormel@kit.nl

${ }^{1}$ Royal Tropical Institute, KIT Health, P.O. Box 95001, 1090 HA Amsterdam, The

Netherlands

Full list of author information is available at the end of the article
}

(c) The Author(s). 2019 Open Access This article is distributed under the terms of the Creative Commons Attribution 4.0 International License (http://creativecommons.org/licenses/by/4.0/), which permits unrestricted use, distribution, and reproduction in any medium, provided you give appropriate credit to the original author(s) and the source, provide a link to the Creative Commons license, and indicate if changes were made. The Creative Commons Public Domain Dedication waiver (http://creativecommons.org/publicdomain/zero/1.0/) applies to the data made available in this article, unless otherwise stated. 


\section{Background}

Pursuit of ambitious global health initiatives, including those related to the 2015 sustainable development goals, led to renewed attention for health systems' weaknesses [1]. Key challenges include public sector human resource shortages and their effects on access to services [2-6]. In response, health systems have (again) turned to engaging community health workers (CHWs) to reach out to underserved communities. The evidence of the potential contribution of CHWs to improving the health of populations is well documented [7-10], and there is renewed attention for the potential of strengthening the performance of CHWs; this is also evidenced by the recent publication of the World Health Organization (WHO) guideline on support to optimise CHW programmes [11].

\section{Community health workers}

CHWs, who often are from low socio-economic backgrounds, have been defined as "any health worker carrying out functions related to health care delivery; trained in some way in the context of the intervention, and having no formal professional or paraprofessional certificate or degree in tertiary education" [8]. In addition, the WHO has suggested CHWs should be supported by the health system even when they are not a formal cadre [12]. They are the first point of contact between health service clients and providers, linking communities to the health system [13, 14]. CHWs deliver a wide range of promotive, preventive and partly curative services, including maternal and child health, HIV care and treatment of malaria $[15,16]$. They are also in the unique position of being able to bring insights about community health to higher-level health workers [17]. CHWs mostly work in public and non-governmental settings in lowand middle-income countries (LMICs).

\section{CHW motivation, performance and incentives}

The ability of CHWs to deliver effective services depends on many different contextual, health system and intervention design factors $[14,16,18,19]$. CHW recruitment, retention and performance are enhanced by, or may even depend on, CHW motivation [20], defined as "an individual's degree of willingness to exert and maintain an effort towards organizational goals" [21]. Motivation in turn is influenced by incentives, which can range from community appreciation to uniforms, volunteer allowances and remuneration, among others $[7,12,17,22,23]$. The diagram in Fig. 1 depicts this relationship [20].

There has been much debate over the type, scope and combination of incentives that would improve $\mathrm{CHW}$ motivation. We define incentives as "the intrinsic and extrinsic factors aimed at positively influencing $\mathrm{CHW}$ motivation" [20, 24].

Extrinsic factors can take the form of financial, material or non-material incentives. Financial incentives range from fixed salaries for those formally employed and allowances for volunteers, to performance-based incentives. Material incentives may include health insurance, clothing or tools of the trade such as boots and backpacks. Non-material incentives include community recognition, preferential treatment and developing new skills. Intrinsic factors relate for example to witnessing positive change and personal growth [12, 24, 25]. Bicycles and other forms of transport, regular supplies, training opportunities and supervision are sometimes also perceived as incentives. We prefer to call these "job enablers", as essentially they constitute the basic resources and enabling environment the health system should make available for CHWs to perform well [12, 20, 24].

Some form of incentives is essential for CHW motivation and programme effectiveness and is expected by CHWs and offered by most organisations [12, 13, 2427]. Some go a step further and argue that paying CHWs is needed to recognise the importance of this role as part of the health system, ensure fairness in terms of "payment for meaningful work" and substantial time investments and in order to provide much needed income in

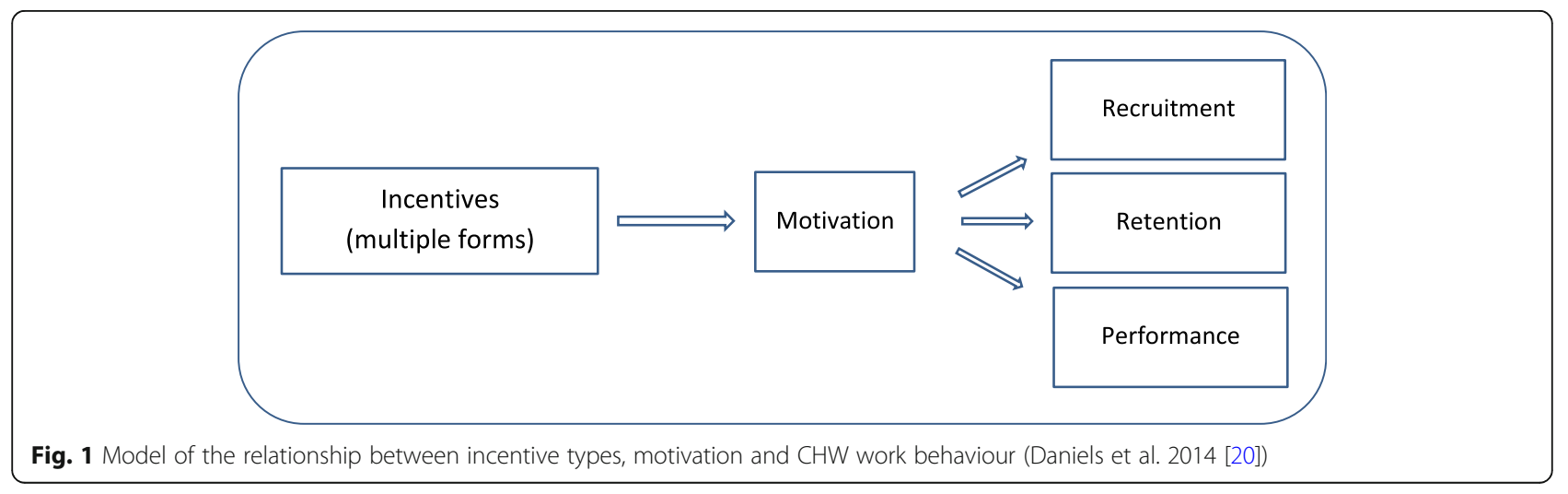


often impoverished settings $[28,29]$. The CHW role is often performed besides multiple (productive and reproductive) responsibilities of women, and some men, in rural areas [17, 30-33]. The new WHO guideline on $\mathrm{CHW}$ programme support also recommends CHWs should receive a financial package [11]. Yet others argue that offering financial incentives is not always an effective or desirable strategy, as this may undermine the volunteering spirit or make clients query CHWs' motives [27, 34-37].

This paper aims to take a critical look at the use of incentives and their link with improving $\mathrm{CHW}$ motivation, and how the salaried vs. volunteer status of CHWs and gaps in $\mathrm{CHW}$ expectations influence this link.

\section{Methods}

This study is a comparative analysis of qualitative studies carried out in Bangladesh, Ethiopia, Kenya, Indonesia, Malawi and Mozambique. These countries were part of the REACHOUT research programme (2013-2018) focusing on factors influencing $\mathrm{CHW}$ performance [38]. The countries have well-established CHW programmes but considerable variation in CHW typology.

In 2013, REACHOUT programme undertook an initial international literature review [39] and developed a conceptual framework modelling the factors influencing health worker performance, with a special focus on CHWs [19, 25]. Using this unifying framework approach [40], the six countries derived topic guides for semi-structured interviews (SSIs) and focus group discussions (FGDs) with purposefully sampled CHWs, their supervisors, health managers and selected community members. SSIs were used to enable individual discussion (and took place in homes and offices) and allowed for sensitive areas to be probed, avoiding possible issues of power which can shape group discussion. FGDs used group interaction to generate findings to help understand community and organisational norms, common health issues and the need for access and use of healthcare services [41]. Sampling of study participants was based on their involvement in CHW programmes; variation was achieved based on demographic characteristics of participants and geographical characteristics of study sites. All six country studies explored participants' perspectives on factors influencing CHW motivation, addressing incentives in terms of expectations and actual (perceived) incentives. Altogether, 250 interviews and 65 FGDs were undertaken as part of the six country qualitative context analyses, referred to as the REACHOUT country studies [42-47]. Details of data collection and respondents per country are presented in Table 1; these as well as details regarding study design (participant selection, setting, data collection), data analysis and reporting can be found in detail in the referred six REACHOUT country study reports.
For the current study, we performed a comparative analysis of the existing datasets of the six country studies, analysing them from various perspectives. We started off with a cross-country review of the six country study reports. To further deepen the themes that emerged from the initial analysis, we then performed secondary data analysis by reviewing existing datasets in Nvivo 10, for codes related to incentives (various forms of incentives and disincentives, motivation, job satisfaction, training, career advancement). Main themes were identified, narratives developed and contextual comparative analyses conducted to explore how the realities of CHWs' role within different countries shaped their experiences and expectations (Table 2).

\section{Results}

Across all six study settings, incentives were found to be an important factor influencing motivation of CHWs and are shaped by three key emerging themes: the mode of $\mathrm{CHW}$ engagement (employed vs. volunteering) influences how various forms of incentives affect each other and motivation, incentive-related "expectation gaps" negatively influence motivation, incentives can cause friction for the interface role of CHWs between communities and the health sector.

\section{The mode of $\mathrm{CHW}$ engagement influences how various forms of incentives affect each other and motivation} Financial incentives were important in all study countries, whether they take the form of salaries or allowances. The appreciation of the salaries CHWs received in Bangladesh, Ethiopia and Malawi as contracted staff demonstrated this. CHWs in Bangladesh, Indonesia, Kenya and Mozambique also welcomed the small monthly volunteering allowance they received.

"Since I am paid my salary, I am committed to serve the community. I am happy when I work hard and take my salary." (Salaried HEW, SSI-Ethiopia)

While salaries were seen as "part of the package" by employed CHWs, voluntary CHWs did not always take their allowance for granted. This was among others the case in Indonesia, where CHWs (kader) said they did not always receive an allowance as per policy.

Material incentives were seen as very important factors affecting CHW motivation. While CHWs sometimes received food or other goods from the communities they served, receipt (or not) of this type of incentive was linked to the organisation they worked with. This often took the form of uniforms and backpacks, as well as job enablers, such as bicycles and standard kits with supplies and drugs. 


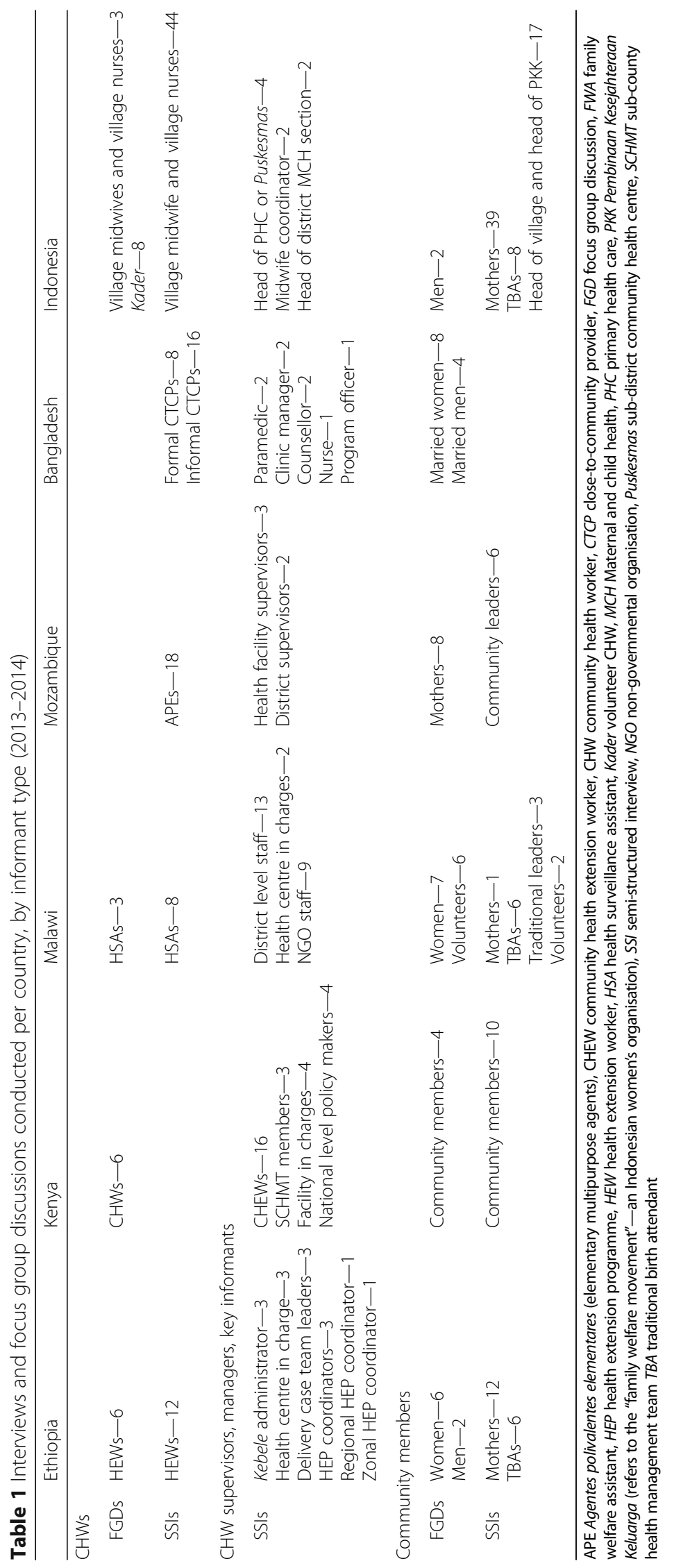




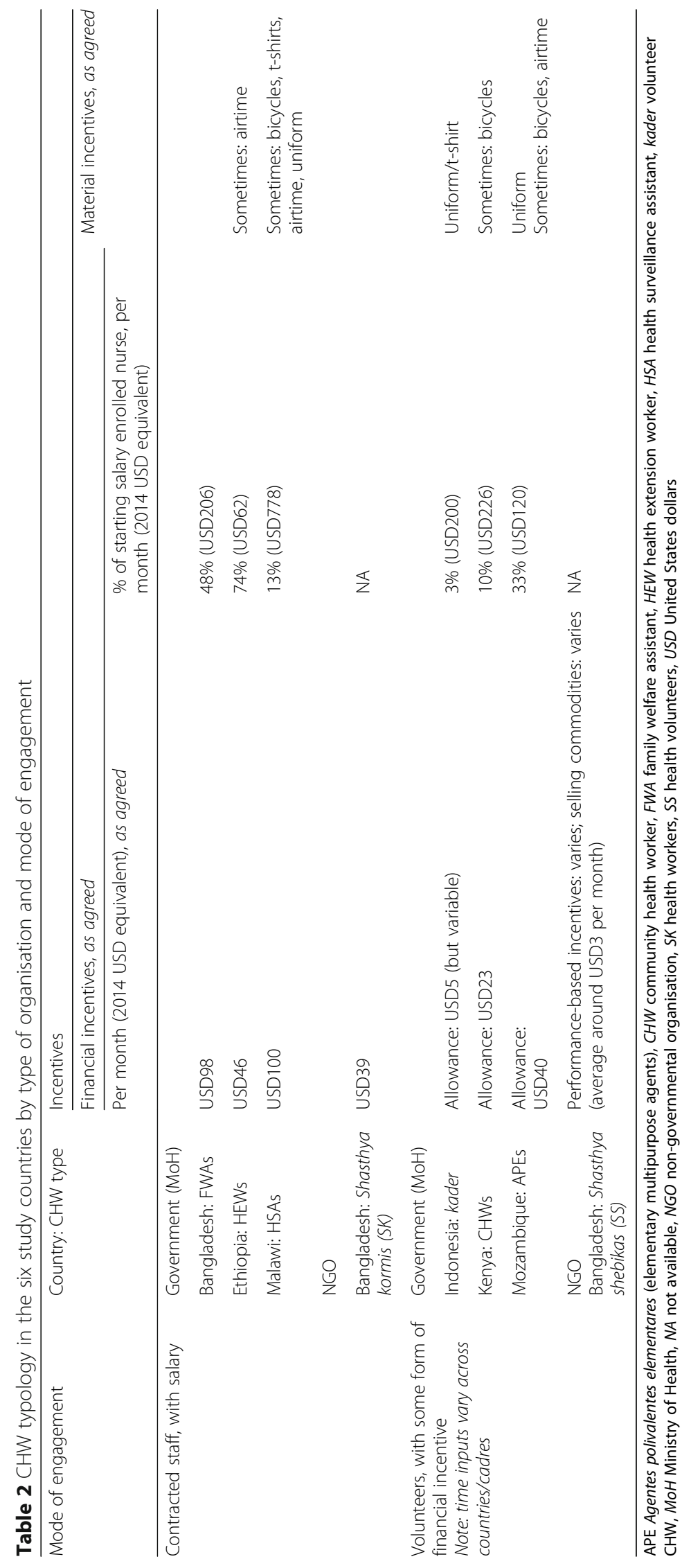


"So those [CHWs] with bicycles, you find they are active. Those who do not have, you find that they are challenged. So I would think if each had a bicycle, it would become a lot better." (Supervisor of voluntary CHWs, SSI-Kenya)

Such material incentives and job enablers not only supported them in their work, but also served to reinforce the standing of community health programmes, both for CHWs and the communities they served.

Material incentives and job enablers were important to employed as well as voluntary CHWs, albeit reasons for this partially differed. For employed CHWs who are sure of receiving a salary, material incentives seemed to be less important; however, the absence of material incentives constituted a disincentive, as we will elaborate below. At the same time, many employed CHWs felt their salary is (too) low, which may make material incentives more important. This also applied to voluntary CHWs, as allowances were usually small. When the intervention design failed to include material incentives, $\mathrm{CHW}$ motivation was hindered and programme effectiveness undermined, regardless of the presence of financial incentives.

"I have seen something that makes [CHWs] not to work well. They don't have transport. They don't have enough support to motivate them. Because the work they do is voluntary." (Supervisor of voluntary CHWs, SSI-Kenya)

CHW respondents in all study countries (regardless of whether they were employed or volunteers) mentioned that they appreciated non-material incentives; many indicated that these helped sustain motivation and made them feel that communities value and appreciate them, recognising the positive contribution of their work.

"A thing that pushes me to work hard is the satisfaction of community by my services. (...) When I see the output of my work, I am very happy." (Salaried HEW, FGD-Ethiopia)

Other examples of non-material incentives were feelings of pride when the community "responds" to health education work and being happy with knowledge and skills obtained, encouragement from supervisors and preferential treatment at the health facility.

Sometimes CHWs received less than expected community appreciation; this was a de-motivator that seemed to affect voluntary CHWs more than those salaried as it hurts the core of the volunteering spirit:

"Those things that don't do me good is that you can get to a certain household and he or she doesn't want to respond. Imagine coming to help, am not paid, have left my own work and then he or she sees me as no one." (Voluntary CHW, FGD-Kenya)

In Bangladesh, most CHWs (both employed and volunteers) reported that being appreciated, recognised and valued by the communities they serve was more important than the financial income they generated through providing these services.

Examples of intrinsic motivational factors were also found in all study countries. Most CHWs desired to assist fellow community members and felt they are useful to their communities; these were major motivational factors, both for salaried and voluntary CHWs. Other intrinsic factors mentioned included love for voluntary work and the perception that as a CHW one is the key link between the health facility and the community and it being "God's will". Some CHWs insisted that monetary incentives were less important than intrinsic motivation; this was more common among voluntary than salaried CHWs.

"The kader have to have the principle that this work is voluntarily done, without asking for salary; if the salary is available, just be grateful." (Voluntary kader, SSI-Indonesia)

In addition, several Kenyan respondents observed that extrinsic incentives and job enablers can sustain intrinsic volunteerism motivation and that lack of such incentives can lead to demotivation.

"This service of a CHW is a calling (...). I have a family, my family needs to eat, my children need to study (...). I do not have a salary, many CHWs live in sad places (...). It is my prayer that we get paid at the end of the month and this will motivate us to work." (Voluntary CHW, FGD-Kenya)

On the other hand, others felt that the introduction of financial incentives could weaken intrinsic motivation of volunteers, as was observed in Indonesia:

"I think they were more active before they got incentives. They worked voluntarily and not for money." (Health manager on voluntary kader, SSI-Indonesia)

\section{Incentive-related "expectation gaps" negatively influence motivation}

In each country setting, employed and voluntary CHWs expressed that when their expectations regarding incentives were not met this negatively affected their motivation. Expectation gaps took various forms: lower than expected financial incentives, later than expected payments, fewer than expected material incentives and job 
enablers and unequally distributed incentives across groups of CHWs.

First, employed CHWs often felt their salaries were too low in comparison with their workload.

"Our salary is very unfair, with our responsibility and the services we are giving for our society." (Salaried HEWs, FGD-Ethiopia)

Many respondents observed the same for voluntary CHWs, who felt that their monetary compensation was (far) below expectations. The importance of financial rewards and disappointment about the amount may also be linked to the poor socio-economic backgrounds the CHWs in our study sites hailed from and whether this work was their primary source of income.

Second, whenever financial incentives of CHWs were expected to be paid but where bureaucratic or other problems caused late disbursements, CHWs became demotivated. Many CHWs reported receiving less than expected or no financial incentives at all; some felt forced to use their own resources to be able to do their job.

"This subsidy is just not enough for anything, but they promised us and should at least give us the little at the end of the month, and they give just nothing. (...) I have to support my family." (Voluntary APE Agente polivalente elementar (elementary multipurpose agent), SSI-Mozambique)

Third, in most of the countries, CHWs observed gaps between promised and received material incentives, such as uniforms and (job enabling) standard kits. Many CHWs also expected other material incentives.

"It requires an HSA to be given transport, identity card, uniform and gumboots as our friends were given but we have never been given." (Salaried HSA, SSI-Malawi)

In all countries, CHWs observed important gaps between expected and actual job enablers, which acted as disincentives for CHWs. CHWs found supportive supervision irregular or not supportive and administration-oriented, in a majority of the countries.

"[What does not please me is] being belittled by my seniors, who see us as nothing and that we are doing this work because we have nothing better to do."

(Voluntary CHW, FGD-Kenya)

CHWs' expectations regarding professional development were often not met, as observed by respondents in Ethiopia, Malawi and Mozambique. Lack of training opportunities was seen as contributing to the lack of career opportunities in the same countries, to CHWs' frustration. In most countries, CHWs' expectations regarding transport for home visits and sometimes also referrals were not met.

"Everybody is developing in his career; we health extension workers remain where we are. (...) These things are pushing us backward not to work hard." (Salaried HEW, FGD-Ethiopia)

"We were promised motorbikes and bicycles and yet they have not been fulfilled. False promises are really frustrating." (Voluntary CHW, FGD-Kenya)

Also, CHWs in Ethiopia, Indonesia, Malawi and Mozambique noted the "inadequate" provision of equipment and regular supplies to perform their duties, leading to frustration and demotivation.

Fourth, as there were no standardised incentive structures for CHWs, incentive-related "competition" between programmes employing CHWs affected motivation negatively.

"Those who are in government facilities get allowances for outreach clinics, while here [at CHAM - Christian Health Association of Malawi] we work for nothing if we go for outreach clinics and in terms of transport. In government facilities they are considered with a motorcycle, but in CHAM not." (Salaried HSA, FGD-Malawi)

Such inequity disturbed the functioning of CHWs, by subverting the incentive structures, thus challenging underlying motivational processes. Another inequity surfaced when CHWs perceived the way material incentives were distributed as unfair, due to favouritism and lack of transparency, as found in Ethiopia, Kenya and Malawi. Ultimately, this undermined motivation and the functioning of community health interventions.

"You will find that [the supervisor] will only invite the few secretly [to receive some compensation] and not all the CHWs. (...) This is something that makes us demotivated and even think of withdrawing because he is not transparent." (Voluntary CHW, FGD-Kenya)

\section{Incentives cause friction for the interface role of $\mathrm{CHWs}$ between communities and the health sector}

CHWs are playing a key facilitation and referral role between communities and the health sector. Incentives were sometimes observed to establish and strengthen relationships and accountability, especially between CHWs and their supervisors. This applied to both salaried and voluntary CHWs. 
Conversely, lack of promised payments sometimes led to mistrust towards those in the health sector, while demotivation sometimes led to reduced community trust in CHWs, thus undermining the effectiveness of community health programmes.

"This job is very hard to do (...). This payment we are supposed to get, the government is the one that is not trustworthy. They should give some money for us to be paid every month." (Voluntary CHW, FGD-Kenya)

A Kenyan key informant observed that absence of a government salary means a (volunteer) CHW cannot be held accountable, in contrast with (salaried) community health extension workers (CHEWs).

"Because CHEWs are paid by the government you can hold them to account, rather than the volunteer [CHW] who can leave an important job half way and you cannot hold him/her accountable because they were volunteering." (Policy maker, SSI-Kenya)

The effect of payment on CHW accountability towards communities remains to be seen; there was some evidence that (perceptions about) payment of CHWs could result in community mistrust.

"The community (...) will regard us as responsible and meaningful people to the community. So even if they say we get paid we just keep silent (...). What I don't like is them mocking me, you can get to some places where they say we are paid and also they are speaking in mockery tones." (Voluntary CHW, FGD-Kenya)

\section{Discussion}

Our study findings from six different contexts contribute to debates on how various types of incentives, alongside job enablers, influence not only motivation but also each other; and what the role is of CHW engagement (salaried vs. voluntary) and the price of "false promises".

Our findings demonstrate that both financial and nonfinancial incentives, independently and together, improve CHW motivation [12, 14, 32]. Monetary compensation is highly valued and directly motivates CHWs to perform better and allows them to dedicate themselves to their jobs, whether in a salaried or volunteering position. Nonfinancial incentives (material and non-material) can, with or without accompanying financial incentives, also contribute to motivation. However, financial incentives alone seem insufficient to maintain motivation and need to be complemented by other types of incentives and job enablers like training and supplies, among others $[11,24,25$, $32,48]$. Both salaried and allowance-receiving voluntary CHWs in all study contexts showed that intrinsic motivational factors were also important to them, confirming findings elsewhere $[24,27,49]$.

Discussion around a volunteering approach vs. providing salaries to CHWs is ongoing [13, 28, 34, 49]. Volunteers are, generally, unlikely to continue to serve without a clear prospect of receiving salaries, especially as expectations in the form of tasks and workload expand [30-32]. Lack of salaries contributes to attrition within voluntary $\mathrm{CHW}$ programmes and makes regular recruitment and training of new volunteers necessary $[13,30,48,50]$.

The mode of engagement of CHWs affects the way incentives influence each other, as well as motivation. Employed, salaried CHWs often seem demotivated due to the perceived low level of monetary reward as compared to workload and living costs [49]. Connectedness to communities serving as intrinsic motivation is important to many salaried CHWs but cannot easily compensate for the perceived low financial reward. The reverse seems true for volunteers: the strong intrinsic motivators identified by many voluntary CHWs prevent them to become dispirited about their modest allowances. Some explicitly indicate such financial incentives are "nice" but not as important as the intrinsic factor driving their volunteering spirit. In contrast, we also found some evidence that extrinsic incentives and job enablers can sustain intrinsic volunteerism motivation and that lack of such incentives can lead to demotivation. At the same time, one statement of a manager in Indonesia implied that the introduction of financial incentives for volunteers who previously did not receive an allowance weakened intrinsic motivation. This potential negative effect of financial incentives has been highlighted by other authors $[24,34,48,49,51,52]$.

While our findings indicate that the way incentives influence motivation depends at least in part on individual behaviour, this is in turn influenced by context. Strachan et al. [53] have argued that CHW motivation may increase relevant to the degree CHWs identify with group membership and share a collective social identity. Their suggestion to use the Social Identity Approach theory to help understand CHW motivation and design related interventions is worthwhile to explore further.

Incentives do not automatically lead to improved motivation as expected. Authors over time have consistently referred to enabling factors that should be present to ensure this [20, 24]. Indeed, our findings suggest that several job enablers need to be in place but often were not, including (i) minimum resources to perform well, such as a functioning supply chain to enable implementation of core tasks (e.g. for test kits and drugs) and some form of transport where distances are unfeasibly long, for CHWs to do their usual work and for CHW clients to be referred; (ii) regular, supportive oriented (as opposed to fault-finding or purely administrative-oriented) 
supervision; and (iii) continuous education and professional development opportunities. Other studies confirm this, also indicating that where any of these job enablers is felt missing or much weaker than anticipated, they are a barrier or disincentive to $\mathrm{CHW}$ performance $[13,17,33,49,54-56]$. The WHO guideline on support to $\mathrm{CHW}$ programmes makes explicit recommendations towards ensuring each of these three enabling areas [11].

In line with the above, Fig. 2 presents our revised, more detailed model to visualise the way incentives interact with each other and with motivation, and the way job enablers and CHW engagement influence incentives and motivation.

The findings confirm that both salaried and voluntary CHWs mostly feel that the monetary compensation they receive is not commensurate with their efforts; this is likely to be an important issue in poor socio-economic contexts. Lower-than-expected incentives and not receiving promised (financial or material) incentives lead to demotivation and are a barrier to performance [37, 57-59]. It is noteworthy that many CHWs appear to feel more strongly about "broken promises" regarding incentives and job enablers, than about the absolute level of incentives received.
Incentive packages therefore should be in line with $\mathrm{CHW}$ job demands, in terms of expectations regarding type and number of tasks, training, as well as expected time investment $[11,33,58]$. As important is that such commitments then also are honoured.

Health systems are increasingly expected to be accountable to the communities they serve. Authors have argued that remuneration may lead to CHWs feeling more accountable towards the health sector than to their communities [60-62]. Reversely, if CHWs engaged by the health system are not paid or otherwise formally embedded, there is no valid mechanism for the system to hold them accountable for their performance [17, 63].

Our findings show that (especially financial but also material) incentives indeed may serve to establish and strengthen relationships of accountability between CHWs and their supervisors within the health system. If financial incentives take the form of a salary tied to a position as government staff, CHWs are well-integrated into the health system and this can lead to increased effectiveness [37]. Conversely, not receiving promised monetary incentives (whether a salary or allowance) in time or not at all creates mistrust towards the health system $[14,48]$.

Financial incentives may also put in jeopardy the accountability relationship with the community. Mistrust

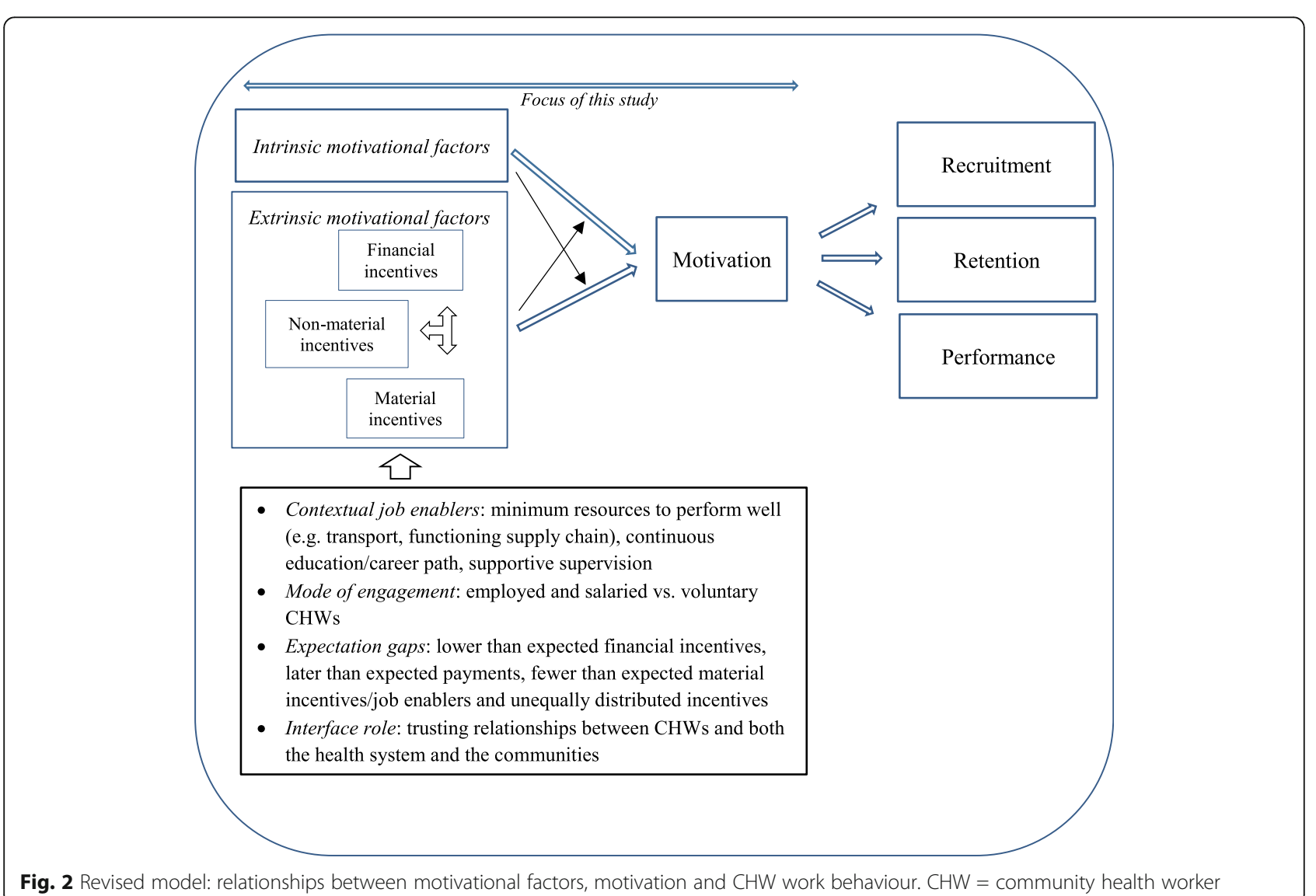

Fig. 2 Revised model: relationships between motivational factors, motivation and CHW work behaviour. CHW = community health worker 
between CHWs and the communities they serve is sometimes created when community members perceive allowances as "salary" and then interpret voluntary CHWs as formally being part of the health sector and make proportionate (demanding) claims on their support. Another study found that community members may sometimes think CHWs withhold money or earn money "behind their backs" [64].

The current paper is based on an analysis of existing datasets from a broader study on factors influencing the performance of CHWs in six country contexts. Although different types of incentives were part of data provided by study respondents, it is possible that more in-depth information about incentives could have added to the appreciation of factors influencing the way incentives operate in the countries studied. While each country study included the same categories of respondents, there were differences in types and gender of respondents between countries (Table 1), which could have influenced the findings. In addition, $\mathrm{CHW}$ programmes across the world have many diverse features and contexts, which pose limitations to the comparison and the generalisability of study findings. To support generalisability, we have tried to provide clear information about the programme features and contexts of the CHW programmes studied in the six countries, and also discussed where findings are common or differing across the six REACHOUT country contexts.

\section{Conclusions}

Whether CHWs are employed or engaged as volunteers has implications for the way incentives influence motivation. While intrinsic motivational factors are important to and experienced by both types of CHWs, for many salaried CHWs, they may not suffice to compensate for the demotivation that often exists and is arising from the perceived low level of financial reward. In some contexts, voluntary CHWs may not take allowances for granted and continue to rely on intrinsic motivation to carry on with their work. Yet overall, introducing and/or sustaining a form of financial incentive seems key towards strengthening $\mathrm{CHW}$ motivation. Such remuneration should then be fair (commensurate to the job demands) and consistent (over time as well as across CHW groups with similar job demands).

There is some evidence that extrinsic incentives and job enablers can sustain intrinsic motivation for volunteerism. Adequate expectation management regarding financial and material incentives as well as job enablers is essential, to prevent frustration about expectation gaps or "broken promises" to negatively affect motivation. For many CHWs, consistently receiving the type and amount of incentives promised appears as important to sustain motivation as raising the absolute level of incentives.

\section{Abbreviations}

APE: Agentes polivalentes elementares (elementary multipurpose agents, Mozambique); CHAM: Christian Health Association of Malawi; CHEW: Community health extension worker (Kenya); CHW: Community health worker; FGD: Focus group discussion; HSA: Health surveillance assistant (Malawi); HEW: Health extension worker (Ethiopia); LMICs: Lowand middle-income countries; NGO: Non-governmental organisation; SSI: Semi-structured interview; WHO: World Health Organization

\section{Acknowledgements}

The authors would like to thank all respondents that participated in the interviews and focus group discussions in the six research countries; and the other members of the country study teams.

\section{Authors' contributions}

All authors were involved in the original design of the six qualitative country studies. RA, KC, SFR, DG, LO and MS were principal investigators for these studies and involved in the data collection. All authors were involved in the data analysis and reporting towards the six-country study reports. $\mathrm{HO}, \mathrm{KDK}$ and MK did the comparative analysis of these six studies and drafted the manuscript. All authors validated the comparative analysis findings and contributed towards revision of the manuscript drafts. All authors read and approved the final manuscript.

\section{Funding}

The REACHOUT Consortium was funded by the European Union FP7 grant (number 306090).

\section{Availability of data and materials}

The datasets generated and analysed during the current study are available from the country study authors on reasonable request; contact details are available through the corresponding author.

\section{Ethics approval and consent to participate}

Ethical clearance was obtained from the Research Ethics Committee at KIT for the generic protocol, and each country obtained ethical clearance from the local ethics committees - Bangladesh: Ethical Review Committee, James P. Grant School of Public Health, BRAC University approval 26 August 2013; Ethiopia: SNNP Regional State Health Bureau ethical approval of 18/10/05 (2005 Ethiopian calendar; 2013 Gregorian calendar); Indonesia: Eijkman Institute Research Ethics Commission approval of 31 July 2013; Kenya: KEMRI Ethics Review Committee approval of 16 August 2013 (KEMRI/RES/7/3/1); Malawi: National Health Sciences Research Committee, approval NHSRC \#1 168 of 6 June 2013; Mozambique: Scientific Council of the Eduardo Mondlane University ethical approval of 3 June 2013. Written informed consent to participate in the study was sought from all interview and focus group participants, in each of the six countries.

\section{Consent for publication}

Not applicable.

\section{Competing interests}

The authors declare that they have no competing interests.

\section{Author details}

${ }^{1}$ Royal Tropical Institute, KIT Health, P.O. Box 95001, 1090 HA Amsterdam, The Netherlands. ${ }^{2}$ Eijkman Institute for Molecular Biology, Jalan Diponegoro 69, Jakarta 10430, Indonesia. ${ }^{3}$ Research for Equity and Community Health (REACH) Trust, P.O. Box 1597, Lilongwe, Malawi. ${ }^{4}$ BRAC James P. Grant School of Public Health, BRAC University, Mohakhali, Dhaka, Bangladesh. ${ }^{5} \mathrm{HHA}-\mathrm{YAM}$, P.O. Box 303, Hawassa, Ethiopia. 'EVCT Health, Research and Strategic Information Department, P.O. Box 19835-00202, Nairobi, Kenya. ${ }^{7}$ Department of Community Health, University Eduardo Mondlane, P.O. Box 257, Maputo, Mozambique. ${ }^{8}$ Department of International Public Health, Liverpool School of Tropical Medicine, Pembroke Place, Liverpool L3 5QA, UK.

Received: 28 February 2019 Accepted: 20 June 2019

Published online: 19 July 2019

\section{References}

1. Buse K, Hawkes S. Health in the sustainable development goals: ready for a paradigm shift? Globalization and health. 2015;11(1):13. 
2. Balabanova D, McKee M, Mills A. Good health at low cost 25 years on. What makes a successful health system? London: London School of Hygiene \& Tropical Medicine; 2011.

3. Campbell J, Dussault G, Buchan J, Pozo-Martin F, Guerra Arias M, Leone C, et al. A universal truth. No health without a workforce. Forum Report, Third Global Forum on Human Resources for Health, Recife, Brazil. Geneva: Global Health Workforce Alliance and World Health Organization; 2013.

4. Campbell J, Admasu K, Soucat A, Tlou S. Maximizing the impact of community-based practitioners in the quest for universal health coverage. Bulletin of the World Health Organization. 2015;93:590-A.

5. Pettigrew LM, De Maeseneer J, Anderson M-IP, Essuman A, Kidd MR, Haines A. Primary health care and the Sustainable Development Goals. The Lancet. 2015;386(10009):2119-21.

6. Tangcharoensathien V, Mills A, Palu T. Accelerating health equity: the key role of universal health coverage in the Sustainable Development Goals. BMC medicine. 2015;13(1):101.

7. Bhutta ZA, Lassi ZS, Pariyo G, Huicho L. Global experience of community health workers for delivery of health-related Millennium Development Goals: a systematic review, country case studies and recommendations for scaling up. Global Health Workforce Alliance: Geneva, Switzerland; 2010.

8. Lewin S, Munabi-Babigumira S, Glenton C, Daniels K, Bosch-Capblanch X, van Wyk BE, et al. Lay health workers in primary and community health care for maternal and child health and the management of infectious diseases. Cochrane database of systematic reviews (Online). 2010;3:CD004015.

9. Perry $\mathrm{H}$, Zulliger R. How effective are community health workers? An overview of current evidence with recommendations for strengthening community health worker programs to accelerate progress in achieving the health-related Millennium Development Goals. Baltimore, USA: Johns Hopkins Bloomberg School of Public Health; 2012.

10. Perry HB, Zulliger R, Rogers MM. Community health workers in low-, middle, and high-income countries: an overview of their history, recent evolution, and current effectiveness. Annual review of public health. 2014;35:399-421.

11. World Health Organization. WHO guideline on health policy and system support to optimize community health worker programmes. Geneva; 2018.

12. Lehmann U, Sanders D. Community health workers: What do we know about them? The state of the evidence on programmes, activities, costs and impact on health outcomes of using community health workers. Geneva, Switzerland: World Health Organization; 2007.

13. Naimoli JF, Perry HB, Townsend JW, Frymus DE, McCaffery JA. Strategic partnering to improve community health worker programming and performance: features of a community-health system integrated approach. Human resources for health. 2015;13(1):46.

14. Kok MC, Broerse JE, Theobald S, Ormel H, Dieleman M, Taegtmeyer M. Performance of community health workers: situating their intermediary position within complex adaptive health systems. Human Resources for Health. 2017;15(1):59

15. Glenton C, Scheel IB, Lewin S, Swingler GH. Can lay health workers increase the uptake of childhood immunisation? Systematic review and typology. Tropical Medicine and International Health. 2011;16(9):1044-53.

16. Kok MC, Dieleman M, Taegtmeyer M, Broerse JE, Kane SS, Ormel H, et al Which intervention design factors influence performance of community health workers in low-and middle-income countries? A systematic review. Health policy and planning. 2014;30(9):1207-27.

17. Theobald S, MacPherson E, McCollum R, Tolhurst R. Close to community health providers post 2015: Realising their role in responsive health systems and addressing gendered social determinants of health. BMC proceedings. 2015:9(10):S8.

18. De Koning K, Kok M, Ormel H, Kane S, Rashid S, Sarker M, et al. A common analytical framework on factors influencing performance of close-tocommunity providers. Synthesis of the inter-country context analysis in Bangladesh, Ethiopia, Indonesia, Kenya, Malawi and Mozambique and the international literature review. Amsterdam: KIT/REACHOUT: http://www. reachoutconsortium.org/media/2859/reachout-inter-country-analysis-andframework-report.pdf

19. Kok MC, Kane SS, Tulloch O, Ormel H, Theobald S, Dieleman M, et al. How does context influence performance of community health workers in lowand middle-income countries? Evidence from the literature. Health Research Policy and Systems. 2015;13(1):13

20. Daniels K, Odendaal WA, Nkonki L, Hongoro C, Colvin CJ, Lewin S. Incentives for lay health workers to improve recruitment, retention in service and performance. The Cochrane Library. 2014;7.
21. Franco LM, Bennett $S$, Kanfer R. Health sector reform and public sector health worker motivation: a conceptual framework. Social science \& medicine. 2002;54(8):1255-66.

22. ERT2. Final report of evidence review team 2. Which formal health system support activities improve the performance of community health workers?: U.S. Government Evidence Summit: Community and Formal Health System Support for Enhanced Community Health Worker Performance; 2012.

23. Palazuelos D, Ellis K, Im DD, Peckarsky M, Schwarz D, Farmer DB, et al. 5SPICE: the application of an original framework for community health worker program design, quality improvement and research agenda setting. Global health action. 2013;6:19658.

24. Bhattacharyya K, Winch P, LeBan K, Tien M. Community health worker incentives and disincentives: how they affect motivation, retention, and sustainability. Arlington: Basic Support for Institutionalizing Child Survival Project (BASICS II) for USAID; 2001.

25. Kok MC, Dieleman M, Taegtmeyer M, Broerse JEW, Kane SS, Ormel H, et al. Which intervention design factors influence performance of community health workers in low- and middle-income countries? A systematic review. Health Policy and Planning. 2014:1-21. https://doi.org/10.1093/heapol/czu126.

26. Peltzer K, Tabane C, Matseke G, Simbayi L. Lay counsellor-based risk reduction intervention with HIV positive diagnosed patients at public HIV counselling and testing sites in Mpumalanga, South Africa. Evaluation and program planning. 2010;33(4):379-85.

27. Singh D, Negin J, Otim M, Orach CG, Cumming R. The effect of payment and incentives on motivation and focus of community health workers: five case studies from low- and middle-income countries. Human resources for health. 2015;13(1):58.

28. Mukherjee JS, Eustache FE. Community health workers as a cornerstone for integrating HIV and primary healthcare. AIDS care. 2007;19(Suppl 1):S73-82.

29. Strachan DL, Kallander K, Ten Asbroek AH, Kirkwood B, Meek SR, Benton L, et al. Interventions to Improve Motivation and Retention of Community Health Workers Delivering Integrated Community Case Management (iCCM): Stakeholder Perceptions and Priorities. The American journal of tropical medicine and hygiene. 2012;87(5 Suppl):111-9.

30. Akintola $\mathrm{O}$. What motivates people to volunteer? The case of volunteer AIDS caregivers in faith-based organizations in KwaZulu-Natal, South Africa. Health policy and planning. 2010;26(1):53-62.

31. Appleford G. Community health workers-motivation and incentives. Development in Practice. 2013;23(2):196-204.

32. Takasugi T, Lee AC. Why do community health workers volunteer? A qualitative study in Kenya. Public health. 2012;126(10):839-45.

33. Lajoie M-RB, Hulme J, Johnson K. Payday, ponchos, and promotions: a qualitative analysis of perspectives from non-governmental organization programme managers on community health worker motivation and incentives. Human resources for health. 2014;12(1):66.

34. Glenton C, Colvin CJ, Carlsen B, Swartz A, Lewin S, Noyes J, et al. Barriers and facilitators to the implementation of lay health worker programmes to improve access to maternal and child health: qualitative evidence synthesis. Cochrane Database of Systematic Reviews. 2013;10:CD010414.

35. Root $R$, van Wyngaard A. Free love: a case study of church-run home-based caregivers in a high vulnerability setting. Global public health. 2011;6(Suppl 2):S174-91.

36. Scott K, Shanker S. Tying their hands? Institutional obstacles to the success of the ASHA community health worker programme in rural north India. AIDS care. 2010;22(Suppl 2):1606-12.

37. Schuster RC, de Sousa O, Rivera J, Olson R, Pinault D, Young SL. Performance-based incentives may be appropriate to address challenges to delivery of prevention of vertical transmission of HIV services in rural Mozambique: a qualitative investigation. Human resources for health. 2016;14(1):60

38. http://www.reachoutconsortium.org [The REACHOUT web page].

39. Kok M, de Koning K, Ormel H, Kane S. International Literature Review. Closeto-community providers. An analysis of systematic reviews on effectiveness and a synthesis of studies including factors influencing performance of CTC providers. Amsterdam: Royal Tropical Institute: http://www. reachoutconsortium.org/media/2856/reachout-international-literaturereview.pdf;; 2014. Accessed 27 June 2019.

40. Dixon-Woods M. Using framework-based synthesis for conducting reviews of qualitative studies. BMC medicine. 2011;9(1):39.

41. Pope C, Mays N. Qualitative research: reaching the parts other methods cannot reach: an introduction to qualitative methods in health and health services research. BMJ (Clinical research ed). 1995;311(6996):42-5. 
42. Gani MS, Sarker M, Siddiqi BA, Mahmud I, Janhangir YT, Theobald S, et al. Context analysis of close-to-community health care service providers in Bangladesh. Dhaka: James P Grant School of Public Health, BRAC Institute of Global Health, BRAC University: http://www.reachoutconsortium.org/media/ 1825/bangladeshcontextanalysisjuly2014compressed.pdf;; 2014.

43. Mireku M, Kiruki M, McCollum R, Taegtmeyer M, Koning KD, Otiso L. Report on the context analysis of close-to-community health service providers in Kenya. Nairobi: LVCT Health: http://www.reachoutconsortium.org/media/ 1837/kenyacontextanalysisjul2014compressed.pdf; 2014.

44. Nasir S, Ahmed R, Kurniasari M, Limato R, de Koning KAM, Tulloch O, et al. Context analysis: close-to-community maternal health providers in South West Sumba and Cianjur, Indonesia. Jakarta: Eijkman Institute for Molecular Biology: http://www.reachoutconsortium.org/media/1831/ indonesiacountryanalysisjuly2014compressed.pdf;; 2014

45. Nyirenda L, Namakhoma I, Chikaphupha K, Kok MC, Theobald S. Report on the context analysis of close-to-community providers in Malawi. Lilongwe: REACH Trust: http://www.reachoutconsortium.org/media/1819/ malawicontextanalysisjuly2014compressed.pdf;; 2014.

46. Sidat M, Ndima S, Taegtmeyer M, Ormel H, McCollum R, Give C. Context analysis report of close-to-community providers in Mozambique. Maputo: University Eduardo Mondlane: http://www. reachoutconsortium.org/media/1834/ mozambiquecountryanalysisjuly2014compressed.pdf;; 2014.

47. Zerihun A, Admassu M, Tulloch O, Kok MC, Datiko DG. Report on the context analysis of close-to-community providers in Ethiopia. Hawassa: HHA-YAM: http://www.reachoutconsortium.org/media/1828/ ethiopiacontextanalysisjuly2014compressed.pdf; 2014.

48. Vareilles G, Pommier J, Marchal B, Kane S. Understanding the performance of community health volunteers involved in the delivery of health programmes in underserved areas: a realist synthesis. Implementation Science. 2017;12(1):22.

49. Greenspan JA, McMahon SA, Chebet JJ, Mpunga M, Urassa DP, Winch PJ. Sources of community health worker motivation: a qualitative study in Morogoro Region, Tanzania. Human resources for health. 2013;11(1):52.

50. Haile F, Yemane D, Gebreslassie A. Assessment of non-financial incentives for volunteer community health workers-the case of Wukro district, Tigray, Ethiopia. Human resources for health. 2014;12:54-60.

51. Kasteng F, Settumba S, Källander K, Vassall A. Group iS. Valuing the work of unpaid community health workers and exploring the incentives to volunteering in rural Africa. Health policy and planning. 2015;31(2):205-16.

52. Taylor C, Griffiths F, Lilford R. Affordability of comprehensive community health worker programmes in rural sub-Saharan Africa. BMJ global health. 2017;2(3):e000391.

53. Strachan DL, Källander K, Nakirunda M, Ndima S, Muiambo A, Hill Z. Using theory and formative research to design interventions to improve community health worker motivation, retention and performance in Mozambique and Uganda. Human resources for health. 2015;13(1):25.

54. Brunie A, Wamala-Mucheri P, Otterness C, Akol A, Chen M, Bufumbo L, et al. Keeping community health workers in Uganda motivated: key challenges, facilitators, and preferred program inputs. Global Health: Science and Practice. 2014;2(1):103-16.

55. Mpembeni RN, Bhatnagar A, LeFevre A, Chitama D, Urassa DP, Kilewo C, et al. Motivation and satisfaction among community health workers in Morogoro Region, Tanzania: nuanced needs and varied ambitions. Human resources for health. 2015;13(1):44.

56. Tripathy JP, Goel S, Kumar AM. Measuring and understanding motivation among community health workers in rural health facilities in India-a mixed method study. BMC health services research. 2016;16(1):366.

57. Saprii L, Richards E, Kokho P, Theobald S. Community health workers in rural India: analysing the opportunities and challenges Accredited Social Health Activists (ASHAs) face in realising their multiple roles. Human resources for health. 2015;13(1):1.

58. Sarin E, Lunsford SS, Sooden A, Rai S, Livesley N. The mixed nature of incentives for community health workers: lessons from a qualitative study in two districts in India. Frontiers in public health. 2016;4:38.

59. George MS, Pant S, Devasenapathy N, Ghosh-Jerath S, Zodpey SP. Motivating and demotivating factors for community health workers: a qualitative study in urban slums of Delhi, India. WHO South-East Asia journal of public health. 2017:6(1):82

60. Cherrington A, Ayala GX, Elder JP, Arredondo EM, Fouad M, Scarinci I. Recognizing the diverse roles of community health workers in the elimination of health disparities: from paid staff to volunteers. Ethnicity \& disease. 2010;20(2):189-94.

61. Glenton C, Scheel IB, Pradhan S, Lewin S, Hodgins S, Shrestha V. The female community health volunteer programme in Nepal: decision makers' perceptions of volunteerism, payment and other incentives. Social science \& medicine (1982). 2010;70(12):1920-7.

62. Maes K. "Volunteers Are Not Paid Because They Are Priceless": Community health worker capacities and values in an AIDS treatment intervention in urban Ethiopia. Medical anthropology quarterly. 2014;29(1):97-115.

63. McCollum R, Otiso L, Mireku M, Theobald S, de Koning K, Hussein S, et al. Exploring perceptions of community health policy in Kenya and identifying implications for policy change. Health policy and planning. 2015;31(2):10-20.

64. Kok MC, Ormel H, Broerse JE, Kane S, Namakhoma I, Otiso L, et al. Optimising the benefits of community health workers' unique position between communities and the health sector: A comparative analysis of factors shaping relationships in four countries. Global public health. 2016; 12(11):1404-32.

\section{Publisher's Note}

Springer Nature remains neutral with regard to jurisdictional claims in published maps and institutional affiliations.

\section{Ready to submit your research? Choose BMC and benefit from:}

- fast, convenient online submission

- thorough peer review by experienced researchers in your field

- rapid publication on acceptance

- support for research data, including large and complex data types

- gold Open Access which fosters wider collaboration and increased citations

- maximum visibility for your research: over $100 \mathrm{M}$ website views per year

At BMC, research is always in progress.

Learn more biomedcentral.com/submissions 